\title{
Complex regional pain syndrome with associated chest wall dystonia: a case report
}

\author{
David J Irwin ${ }^{*}$ and Robert J Schwartzman
}

\begin{abstract}
Patients with complex regional pain syndrome (CRPS) often suffer from an array of associated movement disorders, including dystonia of an affected limb. We present a case of a patient with long standing CRPS after a brachial plexus injury, who after displaying several features of the movement disorder previously, developed painful dystonia of chest wall musculature. Detailed neurologic examination found palpable sustained contractions of the pectoral and intercostal muscles in addition to surface allodynia. Needle electromyography of the intercostal and paraspinal muscles supported the diagnosis of dystonia. In addition, pulmonary function testing showed both restrictive and obstructive features in the absence of a clear cardiopulmonary etiology. Treatment was initiated with intrathecal baclofen and the patient had symptomatic relief and improvement of dystonia. This case illustrates a novel form of the movement disorder associated with CRPS with response to intrathecal baclofen treatment.
\end{abstract}

Keywords: complex regional pain syndrome, dystonia, movement disorder, dyspnea

\section{Background}

Complex regional pain syndrome (CRPS) is most often caused by a fracture or soft tissue injury of an extremity or a surgical procedure [1]. Factor analysis demonstrates that signs and symptoms of the syndrome cluster into four subgroups: 1 ) abnormalities in pain processing that cause allodynia, hyperalgesia and hyperpathia; 2) skin color and temperature change; 3) neurogenic edema, vasomotor and sudomotor abnormalities; and 4) a movement disorder and trophic changes [2]. The movement disorder is manifest as a combination of difficulty initiating and maintaining movement, weakness, postural and intention tremor, myoclonus, spasm, increased tone, abnormalities of reaching and grasping and dystonia $[3,4]$. Dystonia in CRPS is most likely a peripherally induced, focal dystonia [5].

In one study approximately $62 \%$ of CRPS patients were found to have an associated movement disorder, with dystonia being the most common [6]. Dystonia in CRPS patients is most common in the affected limb, with adduction of the arm and flexion of wrist and fingers in the upper extremity and internal rotation of the hip with plantar flexion and inversion of the foot in the lower

\footnotetext{
* Correspondence: dirwin@drexelmed.edu

Drexel University College of Medicine, Department of Neurology, Philadelphia, PA, USA
}

extremity [3]. The presence of dystonia in CRPS patients is associated with longer disease duration and a younger age [6]. The onset of the movement disorder is variable but may precede other manifestations of the disease, and can occur five years or longer after disease onset $[3,6]$.

The presence of dystonia in one extremity increases the risk of dystonia in a second extremity [6], with ipsilateral spread the most common pattern [3]. Generalized forms of dystonia can occur that involve all limbs $[7,8]$; however dystonia of axial muscles (intercostal, pectoralis and oblique muscles) that causes dyspnea has not been reported.

\section{Case Presentation}

The patient is a 51-year-old female who has been followed in neurologic consultation by the author (RJS) since 1987 for her chronic regional pain syndrome. She first presented with a brachial plexus traction injury after a fall. Pain symptoms progressed over the next two years to include total body burning and lancinating pains. At this point she had all factors for diagnosis of CRPS [9].

On physical examination the patient was moderately obese with an anteroflexed body posture and increased carrying angles of the arms. She had a paucity of spontaneous movement. Sensory examination showed severe generalized dynamic and static mechano allodynia and loss of surround inhibition to pinprick and a cold stimulus. 
In addition, she had severe generalized deep muscle sensitization and joint pain. She had hyperalgesia to pinprick and "wind up" as well as cold allodynia in all quadrants of her body. She had longstanding chest pain in the distribution of the intercostobrachial nerve [10]. Autonomic involvement was demonstrated by cold extremities and generalized hyperhidrosis and was associated with moderate neurogenic edema in the lower extremities and livedo reticularis of the skin. Dystonic posturing of the lower extremity was noted early during a few visits and was evidenced by internal rotation of the hip and plantar flexion and inversion of the foot. In addition to overt dystonia, the patient developed ambulatory dysfunction due to weakness and difficulty initiating movements. On one occasion she noted her legs did "not feel like hers." She had difficulty initiating and maintaining fine movements in all extremities. On one visit a postural and intention tremor of the hands and head was noted.

She had failed numerous surgical and medical interventions and developed opiate dependency requiring high doses of intrathecal dilaudid via a subcutaneous pump. Other medical problems included adrenal insufficiency, obstructive sleep apnea that required maintenance on nocturnal bi-level positive airway pressure, chronic gastroparesis, chronic elevation of the right hemidiaphragm, and hypothyroidism.

Approximately twenty-four years after the onset of her CRPS, the patient began having respiratory symptoms of dyspnea on exertion. Palpation of the chest wall showed restrictive chest expansion and sustained contractions of the intercostal musculature, consistent with dystonia. Electromyography (EMG) of the transverses thoraces muscles and paraspinal muscles at T6 and T10 showed normal insertional activity and motor unit morphology. During neurophysiologic testing there was an inability to relax these muscles voluntarily by the patient.

Initial pulmonary function testing showed a mixed restrictive and obstructive picture with a response to bronchodilators (Table 1). Spirometry study met American thoracic society criteria for acceptability [11], with the exception of forced vital capacity on the first study due to fatigue. CT scanning of the chest did not display any features of interstitial lung disease. Echocardiogram showed grade I diastolic dysfunction with no structural heart, valve disease, or pulmonary hypertension.

After receiving a five-day continuous intravenous sub-anesthetic dose of ketamine by infusion $(40 \mathrm{mg} / \mathrm{hr}$; midazolam $4 \mathrm{mg} / 6 \mathrm{hr}$; $0.1 \mathrm{mg}$ of clonidine), her intrathecal dilaudid was gradually weaned from $79 \mathrm{mg} /$ day to $21 \mathrm{mg} /$ day. In addition, intrathecal baclofen was added at an initial dose of $75 \mu \mathrm{g} /$ day. Baclofen was up titrated by approximately $50 \mu \mathrm{g} /$ day every two weeks to a final dose of $600 \mu \mathrm{g} /$ day. The patient experienced symptomatic relief of her chest wall discomfort and dyspnea beginning at doses of $125 \mu \mathrm{g}$ of baclofen per day. Chest wall dystonia was much improved on serial neurologic examinations. Pulmonary function testing results were not significantly changed after baclofen treatment (Table 1). She was maintained at a dose of $600 \mu \mathrm{g} /$ day of intrathecal baclofen and has been asymptomatic in regard to lethargy, weakness, nausea, headaches, or psychosis.

\section{Conclusions}

To our knowledge, this is the first report of dystonia of the chest wall musculature associated with CRPS. The electrodiagnostic evidence of dystonia was limited to patientdependent factors, as the EMG testing showed normal motor unit activation and morphology. It should be noted that the EMG was performed while the patient was receiving $425 \mu \mathrm{g} /$ day of intrathecal baclofen, which could affect motor unit activation. A neurophysiologic study of dystonia in CRPS patients found a similar inability to alter muscle activity voluntarily, in addition to decreased inhibition from activation of antagonist muscle groups [12]. One could argue that the observed inability to relax the chest was musculature was psychogenic; however, voluntary sustained contraction of these axial muscle groups would be very difficult to perform compared to an extremity. In addition, this patient did not display pseudoneurological signs others have argued to be present in CRPS [13].

The significance of the chest wall dystonia in regards to pulmonary symptoms is unclear, but most likely

Table 1 Pulmonary function testing results before and after intrathecal baclofen treatment

\begin{tabular}{|c|c|c|c|c|c|c|c|}
\hline & FVC & FEV1 & FEF $25-75 \%$ & PEF & TLC & RV & DLCO \\
\hline$\frac{\text { Study } 1 \dagger}{\text { Pre-Bronchodilator }}$ & $\begin{array}{l}1.83 \mathrm{~L} \\
\text { (44\% Ref) }\end{array}$ & $\begin{array}{l}1.60 \mathrm{~L} \\
(49 \% \text { Ref) }\end{array}$ & $\begin{array}{l}2.20 \mathrm{~L} / \mathrm{sec} \\
\text { (73\% Ref) }\end{array}$ & $\begin{array}{l}5.34 \mathrm{~L} / \mathrm{sec} \\
\text { (71\% Ref) }\end{array}$ & $\begin{array}{l}2.71 \mathrm{~L} \\
\text { (45\% Ref) }\end{array}$ & $\begin{array}{l}0.88 \mathrm{~L} \\
(40 \% \text { Ref) }\end{array}$ & $\begin{array}{l}12.20 \mathrm{~mL} / \mathrm{mmHg} / \mathrm{min}(44 \% \\
\text { Ref) }\end{array}$ \\
\hline $\begin{array}{l}\text { Post } \\
\text {-Bronchodilator }\end{array}$ & $\begin{array}{l}2.06 \mathrm{~L} \\
\text { (50\% Ref) }\end{array}$ & $\begin{array}{l}1.78 \mathrm{~L} \\
\text { (54\% Ref) }\end{array}$ & $\begin{array}{l}2.44 \mathrm{~L} / \mathrm{sec} \\
\text { (81\% Ref) }\end{array}$ & $\begin{array}{l}4.62 \mathrm{~L} / \mathrm{sec} \\
\text { (62\% Ref) }\end{array}$ & NA & NA & NA \\
\hline $\begin{array}{l}\text { Study } 2+\dagger \\
\text { Pre-Bronchodialtor }\end{array}$ & $\begin{array}{l}1.95 \mathrm{~L} \\
\text { (47\% Ref) }\end{array}$ & $\begin{array}{l}1.57 \mathrm{~L} \\
(49 \% \text { Ref) }\end{array}$ & $\begin{array}{l}1.59 \mathrm{~L} / \mathrm{sec} \\
\text { (53\% Ref) }\end{array}$ & $\begin{array}{l}4.74 \mathrm{~L} / \mathrm{sec} \\
\text { (64\% Ref) }\end{array}$ & $\begin{array}{l}3.07 \mathrm{~L} \\
\text { (52\% Ref) }\end{array}$ & $\begin{array}{l}1.10 \mathrm{~L} \\
\text { (50\% Ref) }\end{array}$ & $\begin{array}{l}11.00 \mathrm{~mL} / \mathrm{mmHg} / \mathrm{min}(36 \% \\
\text { Ref) }\end{array}$ \\
\hline $\begin{array}{l}\text { Post } \\
\text {-Bronchodilator }\end{array}$ & $\begin{array}{l}2.18 \mathrm{~L} \\
\text { (53\% Ref) }\end{array}$ & $\begin{array}{l}1.79 \mathrm{~L} \\
\text { (55\% Ref) }\end{array}$ & $\begin{array}{l}1.97 \mathrm{~L} / \mathrm{sec} \\
\text { (66\% Ref) }\end{array}$ & $\begin{array}{l}4.89 \mathrm{~L} / \mathrm{sec} \\
(66 \% \text { Ref })\end{array}$ & $\mathrm{NA}$ & $\mathrm{NA}$ & $\mathrm{NA}$ \\
\hline
\end{tabular}

† Patient intrathecal medication dose at time of study: Baclofen $0 \mu \mathrm{g} / \mathrm{day}$, Dilaudid $26.5 \mathrm{mg} /$ day.

t† Patient intrathecal medication dose at time of study: Baclofen $400 \mu \mathrm{g} /$ day, Dilaudid $21.5 \mathrm{mg} /$ day. 
contributes in part to the restrictive pulmonary function pattern observed. Patients with idiopathic and secondary dystonia have been noted to have excessive contractions of the diaphragm and upper airways contributing to symptoms of dyspnea [14]. This patient also had obstructive features and a response to bronchodilators, which most likely represents concomitant asthmatic disease. There was no intrinsic disease of the lung parenchyma on CT scanning that could be responsible for her obstructive and restrictive pulmonary function. Vocal cord involvement as a cause for her dyspnea was also unlikely, as there was no dysphonia. Her body habitus, chest wall pain, and paralysis of the right hemi-diaphragm can also contribute to restrictive lung disease. The diaphragm paralysis in this patient is most likely another manifestation of dystonia as spasmodic contraction of the diaphragm may be seen in dystonic patients [14].

The mechanism of dystonia in CRPS is not completely understood but is generally thought to involve neural circuits that mediate sensory-motor integration [15-17]. Recent studies demonstrate impaired inhibition both at cortical and spinal cord levels [18-20]. Present evidence suggests that a major component of the mechanism of dystonia in CRPS involves disinhibition of painful nociceptive withdrawal reflexes in the spinal cord [6]. These reflexes are initiated by activity in $\mathrm{C}$ and A-delta primary pain fibers that colocalize vasoactive neuropeptides with glutamate and are also pivotal in neurogenic inflammation [21]. Substance P is released from pain afferents and activates NK1 receptors on lamina I neurons of the dorsal horn that is important in the induction of long term potentiation of these pain transmission neurons [22]. Evidence of spinal cord inflammation has been demonstrated in CRPS patients who have increased levels of inflammatory cytokines in their spinal fluid [23,24]. Pathologic examination of a severe longstanding CRPS patient has shown microglial and astrocytic activation most prominent at the segmental level of injury, but also as a gradient spread throughout the spinal cord bilaterally [25]. It is possible that this inflammatory activation of the spinal cord resulted in dystonia of the axial musculature through disinhibition of GABAergic inhibitory neurons of the dorsal horn at thoracic levels mediated by SP and inflammatory cytokines. The presented patient has suffered with CRPS for over twenty years and the one autopsied had a six year course suggesting that axial dystonia is a late manifestation of the syndrome.

Intrathecal baclofen is effective in treatment of the limb dystonia of CRPS at a mean dose of $415 \mu \mathrm{g} /$ day [26]. Our patient responded at $600 \mu \mathrm{g} /$ day. Symptomatic improvement from intrathecal baclofen implicates spinal cord involvement in this form of dystonia. Its greatest concentration is in the dorsal horn of the spinal cord in primary afferent fibers [27]. The axial dystonia seen in this patient suggests a link between immune mediated cytokine release and substance $\mathrm{P}$ activation of nocifensor reflexes in the thoracic cord in the axial dystonia of CRPS.

\section{Consent}

Written informed consent was obtained from the patient for publication of this case report. A copy of the written consent is available for review by the Editor-in-Chief of this journal

\section{Acknowledgements}

There was no private or public funding for this study.

\section{Authors' contributions}

RJS formulated the project. DI and RJS contributed in taking the patient history, physical exam, and preparation of the manuscript. All authors read and approved the final manuscript.

\section{Competing interests}

The authors declare that they have no competing interests.

Received: 1 March 2011 Accepted: 26 September 2011

Published: 26 September 2011

\section{References}

1. Schwartzman RJ, Patel M, Grothusen JR, Alexander GM: Efficacy of 5-day continuous lidocaine infusion for the treatment of refractory complex regional pain syndrome. Pain Med 2009, 10(2):401-412.

2. Harden RN, Bruehl S: Diagnostic criteria: the statistical derivation of the four criterion factors. In CRPS: Current Diagnosis and Therapy. Edited by: Wilson, PR, Stanton-Hicks, MD, Harden, RN. Seattle: IASP Press; 2005:45-58.

3. Schwartzman RJ, Kerrigan J: The movement disorder of reflex sympathetic dystrophy. Neurology 1990, 40(1):57-61.

4. Van Hilten JJ, Blumberg HPD, Schwartzman RJ: Factor IV: Movement disorders and dystrophy: clinical and pathophysiological aspects. In CRPS: Current Diagnosis and Therapy. Edited by: Wilson, PR, Stanton-Hicks, MD, Harden, RN. Seattle: IASP Press; 2005:45-58.

5. Schott GD: Peripherally-triggered CRPS and dystonia. Pain 2007, 130:203-207.

6. van Rijn MA, Marinus J, Putter H, van Hilten JJ: Onset and progression of dystonia in complex regional pain syndrome. Pain 2007, 130(3):287-293.

7. van Hilten JJ, van de Beek WJ, Roep BO: Multifocal or generalized dystonia in complex regional pain syndrome: a distinct clinical entity associated with HLA-DR 13. Ann Neurol 2000, 48:113-116.

8. van Hilten JJ, van de Beek WJ, Vein AA, van Dijk JG, Middelkoop HA: Clinical aspects of multifocal or generalized tonic dystonia in reflex sympathetic dystrophy. Neurol 2001, 56:1762-1765.

9. Harden RN, Bruehl S, Stanton-Hicks M, Wilson PR: Proposed new diagnostic criteria for complex regional pain syndrome. Pain med 2007, 8:326-331.

10. Rasmussen J, Grothusen JR, Rosso AL, Schwartzman RJ: Atypical chest pain: evidence of intercostobrachial nerve sensitization in complex regional pain syndrome. Pain Phys 2009, 12:e329-e324.

11. Standardization of spirometry- 1987 update: Official statement of the American Thoracic Society. Respir Care 1987, 32(11):1039-1060.

12. van de Beek WJ, Vein A, Hilgevoord AA, van Dijk JG, van Hilten BJ: Neurophysiologic aspects of patients with generalized or multifocal tonic dystonia of reflex sympathetic dystrophy. J Clin Neurophysiol 2002, 19(1):77-83.

13. Verdugo R, Ochoa JL: Abnormal movements in complex regional pain syndrome: assessment of their nature. Muscle Nerve 2000, 23:198-205.

14. Braun N, Abd A, Baer J, Blitzer A, Stewart C, Brin M: Dyspnea in dystonia: a functional evaluation. Chest 1995, 107(5):1309-1316.

15. Mink JW: Abnormal circuit function in dystonia. Neurol 2006, 66(7):959.

16. Huang YZ, Trender-Gerhard I, Edwards MJ, et al: Motor system inhibition in dopa-responsive dystonia and its modulation by treatment. Neurol 2006, 66(7):1088-1090 
17. Tisch $S$, Limousin $P$, Rothwell JC, et al: Changes in forearm reciprocal inhibition following pallidal stimulation for dystonia. Neurol 2006, 66(7):1091-1093.

18. van de Beek WJ, Vein A, Hilgevoord AJ, van Dijk G, van Hilten B: Neurophysiologic aspects of patients with generalized or multifocal tonic dystonia of reflex sympathetic dystrophy. J Clin Neurophysiol 2002, 19(1):77-83.

19. Schouten AC, Van de Beek WJ, Van Hilten JJ, Van der Helm FC: Proprioceptive reflexes in patients with reflex sympathetic dystrophy. Exp Brain Res 2003, 151(1):1-8.

20. Schwenkreis $P$, Janssen $F$, Rommel $O$, et al: Bilateral motor cortex disinhibition in complex regional pain syndrome (CRPS) type I of the hand. Neurol 2003, 61(4):515-519.

21. Weber M, Birklein F, Neundorfer B, Schmelz M: Facilitated neurogenic inflammation in complex regional pain syndrome. Pain 2001, 91(3):251-257.

22. Schouenborg J: Learning in sensorimotor circuits. Curr Opin Neurobiol 2004, 14(6):693-697.

23. Alexander GM, van Rijn MA, van Hilten JJ, Perreault MJ, Schwartzman RJ: Changes in cerebrospinal fluid levels of pro-inflammatory cytokines in CRPS. Pain 2005, 116:213-219.

24. Alexander GM, Perreault MJ, Reichenberger ER, Schwartzman RJ: Changes in immune and glial markers in the CSF of patients with complex regional pain syndrome. Brain Behav. Immun 2007, 21:668-676.

25. Del Valle L, Schwartzman RJ, Alexander G: Spinal cord histopathological alterations in a patient with complex regional pain syndrome. Brain Behav. Immunity 2009, 23:85-91.

26. van Rijn MA, Munts AG, Marinus J, Voormolen JHC, de Boer KS, TeepeTwiss IM, van Dasselaar NT, Delhaas EM, van Hilten JJ: Intrathecal baclofen for dystonia of complex regional pain syndrome. Pain 2009, 143:41-47.

27. Malcangio M, Bowery NG: GABA and its receptors in the spinal cord. Trends Pharmacol Sci 1996, 17:457-462.

doi:10.1186/1749-7221-6-6

Cite this article as: Irwin and Schwartzman: Complex regional pain syndrome with associated chest wall dystonia: a case report. Journal of Brachial Plexus and Peripheral Nerve Injury 2011 6:6.

\section{Submit your next manuscript to BioMed Central and take full advantage of:}

- Convenient online submission

- Thorough peer review

- No space constraints or color figure charges

- Immediate publication on acceptance

- Inclusion in PubMed, CAS, Scopus and Google Scholar

- Research which is freely available for redistribution

Submit your manuscript at www.biomedcentral.com/submit
Biomed Central 